\title{
Bir Eğitim ve Araştırma Hastanesi Çalışan Sağlığı Biriminde Değerlendirilen Personelin Genel Sağlık Durumunun, Yakınmalarının ve Sık Görülen Hastalıklarının İncelenmesi
}

Investigation of The General Health Status, Complaints and Common Diseases of Personnel Who Evaluated in the Employee Health Unit of A Training and Research Hospital

\author{
Mehmet Pekdemirr ${ }^{1}$, Neşe Aşıcı², Abdülkadir Aydın³ ${ }^{3}$ Elif Köse², Hasan Çetin Ekerbiçer ${ }^{2}$ \\ ${ }^{1}$ Kütahya Hisarcık Aile Sağlı̆̆ı Merkezi, Kütahya \\ ${ }^{2}$ Sakarya Üniversitesi Tip Fakültesi, Halk Sağlığı AD, Sakarya \\ ${ }^{3}$ Sakarya Üniversitesi Eğitim ve Araştırma Hastanesi, Aile Hekimliği, Sakarya
}

Yazışma Adresi / Correspondence:
Neşe Aşıc1
Sakarya Üniversitesi Eğitim ve Araştırma Hastanesi Merkez Kampüsü / Sakarya
T: +90 $5057677768 \quad$ E-mail : nesea@ @sakarya.edu.tr
Geliş Tarihi / Received : 01.06.2020 Kabul Tarihi / Accepted : 29.06.2020
Orcid :
Mehmet Pekdemir, https://orcid.org/0000-0002-0441-2681
Neșe Așıc1, https://orcid.org/0000-0003-0266-6845
Abdülkadir Aydın, https://orcid.org/0000-0003-0663-586X
Elif Köse, https://orcid.org/0000-0002-2232-4538
Hasan Çetin Ekerbiçer, https://orcid.org/0000-0003-0064-3893
Sakarya Tip Dergisi / Sakarya Med J 2020, 10(Özel Say1):41-50) DoI: 10.31832/smj.746231

Öz

Amaç Bu çalıșmada, 2017 yılında bir eğitim ve araștırma hastanesi çalıșan sağlığı biriminde değerlendirilen sağlık çalısanlarının bilgi formları incelenerek, genel sağlık durumlarının, bazı sosyodemografik özelliklere göre yakınma ve kronik hastalık sıklıklarının hesaplanması, iş kazası sıklığı ve özelliklerinin belirlenmesi amaçlanmıștır.

Gereçve Epidemiyolojik tanımlayıcı tipteki bu araştırmada, 2017 yılında, Sakarya Üniversitesi Eğitim ve Araştırma Hastanesi çalışan sağlığı biriminde değerlendirilen sağlık

Yöntemler personeline ait, çalıșan sağlığı bilgi formları incelemeye alınmıştır. Çalışma analizine 549 kişi dâhil edilip, SPSS (20.0) paket programı kullanılarak veri tabanı oluşturulmuş ve istatistiksel anlamlllık $p<0,05$ kabul edilmiștir.

Bulgular Katılımcların \%78,7'si kadın, yas ortalaması 34,74 +8,67 SS, \%71,9'u ebe ve hemşiredir. Katılımcıların \%36,7'si en az bir kronik hastalık beyan etmistir. En sık semptom $\% 27,2^{\prime}$ lik oranla eklem ağrısı olurken, ardından \%19,6 ile sırt ağrısı gelmiștir. Ayrıca alerji (ilaç, lateks, diğer) sıklığının \%23,2 olduğu ve çalışanların \%7,1'inin meslek hayatları boyunca en az bir kez iş kazası geçirdiği saptanmıştır.

Sonuç Sağlık çalışanlarında, hastanelerdeki artmış tehlike ve risk etmenlerinin yanı sıra yaptıkları işin de etkisiyle, özellikle kas iskelet sistemi hastalıkları, kesici-delici alet yaralanmaları, deri hastalıkları ve solunum sistemi hastalıkları sıklıkla izlenmektedir. Ancak yine de iș kazası görülme sıklığının beklenenden düșük olması nedeniyle, çalıșan sağlığı bilgi formuna sağlık alanında sık görülen iș kazası tipleri eklenebilir. Katılımcıların șiddeti iș kazası olarak belirtmediği görüldüğünden, çalıșanların tehdit, fiziksel, sözel vb. şiddete uğrayıp uğramadıkları sorgulanabilir. Farklı sağlı meslek gruplarında olmanın ve hastanenin farklı bölümlerinde çalışmanın, kendilerine özgü riskleri olacağından bunlara özel sorgulama formları oluşturulabilir.

Anahtar Sağlık Çalışanları; Risk Faktörleri; İş Kazaları; Meslek Hastalıkları; Kas İskelet Hastalıkları

Abstract

Objective In this study, it was aimed to investigate the general health status, the frequency of complaints and chronic illnesses of the occupational health unit evaluated in a training and research hospital employee health unit in 2017, and to determine the frequency and characteristics of work accidents.

Materials In this epidemiological descriptive study, it was reviewed the health data sheets of healthcare personnel who evaluated in the employee health unit of Sakarya Training and Research Hospital in 2017. In the study analysis 549 people were included, SPSS (20.0) package program was used to create a database and statistical significance was accepted as, $p<0,05$.

Results $\quad 78,7 \%$ of the participants were female, the mean age was $34,74 \pm 8,67 \mathrm{SD}, 71,9 \%$ were midwives and nurses. $36,7 \%$ of the participants reported at least one chronic disease. The most common symptom was joint pain with a rate of $27,2 \%$, followed by back pain with $19,6 \%$. In addition, it was found that the rate of allergy (drug, latex, other) was $23,2 \%$ and $7,1 \%$ of the employees had at least one work accident during their professional life.

Conclusion In addition to the increased risk and risk factors in hospitals, as well as the effects of their work, especially musculoskeletal diseases, cutaneous penetrating injuries, skin diseases and respiratory diseases are frequently observed in healthcare workers.. Nevertheless, as the incidence of work-related accidents is lower than expected, occupational health information form can be added to the types of occupational accidents common in the field of healthcare. Due to, it is seen that the participants do not indicate the violence as an occupational accident, it can be questioned whether the employees are exposed to violence like physical, verbal or threatening.. Because of being in different health professional groups and working in different parts of the hospital will have their own risks, specific inquiry forms can be created for them. 


\section{GIIRIŞ}

Sağlık çalışanı, hastalara, doku parçalarına, kontamine tıbbi araç-gereç, donanım, çevre yüzeyi hatta hava yoluyla bulaşıcı etmenlere maruziyet riski olan, sağlık hizmet sektöründe çalışan, ücretli ve ücretsiz kişilerin tümü şeklinde tanımlanmaktadır. ${ }^{1}$

Uluslararası Çalışma Örgütü (International Labour Organization-ILO), sağlık hizmet sektöründe çalışanları, hekimler, diğer profesyonel meslek grupları (eczacı, diş hekimi, psikolog), ebe, hemşire, sağlık memuru, diğer sağlık görevlileri ( radyoloji, laboratuar, odyoloji, EEG, EKG teknisyenleri vb. ) ve diğer sağlık çalışanları ( diyetisyen, tıbbi sekreter, güvenlik personelleri vb. ) biçiminde sınıflandırmıştır. ${ }^{2}$

Sağlık Bakanlığ 1 Personel Genel Müdürlüğü istatistiklerine göre 2018 yılı itibariyle Türkiye'de 1.061 .635 sağlık çalışanı bulunmaktadır. Açıklanan verilere göre toplam hekim sayısı 153.128, diş hekimi sayısı 30.615, hemşire sayısı 190.499, eczacı sayısı 32.032, ebe sayısı 56.351, diğer sağlık personeli 177.409, diğer personel ve hizmet alımı 376.367 kişi şeklinde olmuştur. ${ }^{3}$

Son yıllarda ülkemizdeki sosyal ve ekonomik gelişmelerle birlikte sağlık sektöründe çalışan sayısı açısından dünyada önemli noktalara gelinmiştir.

Özkan Ö ve ark. yaptıkları bir çalışmada, Ulusal Mesleki Sağlık ve Güvenlik Enstitüsü ( National Institute for Occupational Safety and Health-NIOSH ) ve Amerika Birleşik Devletlerideki ( ABD ) Mesleki Sağlık ve Güvenlik Birliği ( Occupational Safety and Health Administration- OSHA )'nin hastanelerdeki düzenlemelerin, çalışanlarının sağlığını korumaktan ziyade, hastaları korumaya yönelik yapıldığını ve bu durumun çalışanların sağlığı bakımından ayrı bir tehdit unsuru oluşturduğu tanımlamalarına dikkat çekmiştir. ${ }^{4}$

Sağlık çalışanlarının mesleki risklerinde yapılan işe, mesle- ğe, çalışılan bölüme göre farklılıklar izlenmektedir. Örnek vermek gerekirse; ameliyathane çalışanları için solunan anestezik gazlar, sterilizasyon birimlerinde çalışanlar için gluteraldehid ve civaya maruz kalma risk oluştururken, nükleer tıp ve radyoloji departmanı çalışanları için radyasyonun zararlı etkileri ön plandadır. Bakım hizmetlerini yerine getirirken hastayla geçirdikleri zaman fazla olduğu için hemşirelerin sağlik riskleri ile karşılaşma ihtimalleri diğer sağlık personellerine kıyasla daha fazladır. ${ }^{5}$

Sağlık çalışanlarında iş kazası ve meslek hastalıkları oranının yüksek olması, sağlık hizmetlerinde insan ile birebir çalışılması nedeniyledir. Diğer sektörlerde işin kendi etkisinin daha fazla olduğu izlenmektedir. ${ }^{6}$

Amerikan Çalışma İstatistikleri Bürosu verilerine göre ( Bureau of Labor Statistics-BLS ), ABD'de sağlık çalışanlarının karşılaştığı iş kazası ve meslek hastalıkları oranları, üretim sektöründe gerçekleşen iş kazası ve meslek hastalıkları oranlarına eşit veya daha yüksektir. ABD hastanelerinde sağlık çalışanlarının \% 8,8'i, evde bakım hizmetleri veren hemşirelerin \% 13,5' $\mathrm{i}$ iş kazası veya meslek hastalığ ${ }^{-}$ na maruz kalmakta ya da işinden uzak kalmaktadır. Bahsedilen oranların madencilikte $\% 4$, inşaatta $\% 7,9$ ve üretim sektöründe ( sanayi ) \% 8,1 olduğu düşünüldüğünde; sağlık çalışanları bakımından iş kazası ve meslek hastalıklarının önemi ortaya çıkmaktadır. ${ }^{7}$

Sağlık çalışanları çalışma ortamı, çalışma koşulları ve çalışma ilişkilerinden kaynaklanan; gürültü, aydınlatma ve iyonize radyasyon gibi fiziksel; anestezik ajanlar, farmasötikler, kemoterapik ilaçlar, sterilizatörler ve civa gibi kimyasal; Hepatit B, Human Immmunodeficiency Virus ( HIV ), tüberküloz ve diğer bulaşıcı hastalıklar gibi biyolojik; çalışma ortamının uygun şekilde dizayn edilmemesinin neden olduğu ergonomik; vardiya sistemi ile çalışma, yalnız çalışma, stresli ortamlarda çalışma gibi psikososyal; ücretlerin düşük olması, kreş- lojman vb.imkanlarının olmaması gibi sosyal güvenlik ile ilişkili birçok risk ve sağlık sorunu ile karşılaşabilmektedir. ${ }^{8}$ 
Bu çalışmada, 2017 yılında bir eğitim araştırma hastanesi çalışan sağlığı birimindeki bilgi formları incelemeye alınarak sağlık çalışanlarının, genel sağlık durumlarının incelenmesi, bazı sosyodemografik özelliklere göre yakınma ve kronik hastalık sıklıklarının hesaplanması, iş kazası sıklığı ve özelliklerinin belirlenmesi amaçlanmıştır.

\section{GEREÇ ve YÖNTEMLER}

Epidemiyolojik tanımlayıcı tipteki bu araştırma, Sakarya Eğitim Araştırma Hastanesi (SakaryaEAH) çalışan sağlı̆̆ biriminde, kurum personelinin değerlendirildiği çalışan sağlığı bilgi formları üzerinden yapılmıştır. Formun içeriğinin hazırlanmasında 20.07.2013 tarihinde yürürlüğe giren, 28713 sayılı; İşyeri Hekimi Ve Diğer Sağlık Personelinin Görev, Yetki, Sorumluluk Ve Eğitimleri Hakkındaki Yönetmelik'te yer alan Ek-2, İşe Giriş/Periyodik Muayene Formu örnek alınmıştır.

Araştırma, SakaryaEAH Merkez, Korucuk, Kadın Doğum ve Çocuk Hastalıkları Kampüslerinde çalışan ve 2017 yılında SakaryaEAH çalışan sağlığı biriminde değerlendirilen; 33 doktor, 315 hemşire, 76 ebe, 8 sağlık memuru, 24 röntgen, 14 anestezi, 47 laboratuvar teknisyeni, 8 sağlık memuru, 6 hizmetli, 6 sağlık teknikeri, 6 radyoloji teknikeri, 6 diğer personel, 3 tıbbi sekreter toplam 549 kişi için doldurulan Ek-2 benzeri çalışan sağlığı bilgi formları, etik kurul onayı ve ilgili kurumdan yazılı izin alınarak, 01.04.2018 - 30.06.2018 tarihleri arasinda incelenmek suretiyle yapilmıştır. Ek-2 benzeri bu formda, çalışanların sosyodemografik özellikleri, daha önceki iş geçmişi, özgeçmişi ( kan grubu, kronik hastalık, konjenital hastalık, geçirilmiş diğer hastalıklar, alerji ve bağışıklık durumu ) soygeçmişi ( ailede diyabet, hipertansiyon, koroner arter hastalığg, kanser ) sorgulanmaktadır. Tıbbi anemnezin yanında, balgamlı öksürük, nefes darlığı, göğüs ağrısı, çarpıntı, sırt ağrısı, ishal/ kabızlık, eklemlerde ağrı gibi yakınmaları daha önce kalp hastalığı, şeker hastalığı, böbrek rahatsızlığı, sarılık, mide/ duodenum ülseri teşhisi konulup konulmadığı, işitme kaybı, görme bozukluğunun olup olmadığg sinir sistemi hastalığı, deri hastalığı, besin zehirlenmesi olup olmadığı bilgileri bulunmaktadır. Daha önceki hastane yatışları, geçirilmiş ameliyatlar, iş kazası durumu, maluliyet durumları, meslek hastalıkları şüphesiyle muayene olma durumu, şu an tedavi görme durumu ile sigara, alkol, madde kullanım alışkanlıkları sorgulanmaktadır. Form ayrıca genel sistem muayenesi; tansiyon arteryel, nabız, boy, kilo ölçümü, beden kitle indeksi ile hemogram, açlık kan şekeri düzeylerini içermektedir.

Çalışmaya katılanlarda hipertansiyon sıklığı hesaplanırken, hipertansiyon tanısı için kan basıncının 140/90 mm $\mathrm{Hg}$ ve üzerinde olması veya antihipertansif tedavi alıyor olmak veya daha önce hipertansiyon tanısının konmuş olması kriteri kullanılmıştır. ${ }^{9}$

Obezite sıklığını hesaplarken ise ağırlık ve boyun birlikte ele alındığı Beden Kitle İndeksi ( BKİ ), ağırlık ( kg ) / boy( $\mathrm{m}$ )2 formülü kullanılmıştır. Dünya Sağlık Örgütü ( DSÖ )'ne göre BKİ değeri < 18.5 olanlar “zayıf”, 18.524.9 olanlar "normal ağırlıklı", 25.0-29.9 olanlar "fazla kilolu (preobez)" ve $\geq 30$ olanlar "obez" olarak tanımlanmıs olup, 30,00-34,99 “obez sinif 1", 35,00 - 39,99 “obez sinif 2", $\geq 40,00$ "obez sinıf 3 " olarak değerlendirilmektedir. ${ }^{10}$

Diyabet tanısı için, diyabet öyküsü, ilaç kullanma durumu ve Açlık Kan Şekeri ( AKŞ ) baz alınmıştır. AKŞ değerleri diyabet için $126 \mathrm{mg} /$ dl ve üzeri olarak alınmıştır. ${ }^{11}$

Araştırmada SPSS v20.0 ( IBM SPSS Statistics for Windows, Version 20.0; Armonk, NY, USA ) paket programı kullanılarak veri tabanı oluşturulmuştur. Değişkenlerin normal dağılıma uygunluğu Kolmogorov-Smirnov test yöntemiyle incelenmiş olup, tanımlayıcı analizlerde normal dağılan değişkenler için aritmetik ortalama \pm standart sapma, normal dağılmayan değişkenler için ise ortanca ve çeyrekler arası genişlik kullanılmıştır. Kategorik değişkenler sayı ( $n$ ) ve yüzdelerle ( \% ) belirtilmiştir. Sürekli değişkenlerde grupların ortalamaları arasındaki farkın anlamlılı̆̆ını değerlendirmede; normal dağılım gösteren bağımsız gruplarda Student t-testi kullanılmıştır. Kategorik 
değişkenler arasındaki farkın anlamlılığını test etmek için Pearson ki-kare testi kullanılmıştır. İstatistiksel anlamlılık $\mathrm{p}<0,05$ kabul edilmiştir.

Çalışma için T.C Sakarya Üniversitesi Tip Fakültesi Girişimsel Olmayan Araştırmalar Etik Kurulun'dan 71522473/050.01.04/82 karar sayılı ve 02.04.2018 tarihli etik kurul onayı alınmıştır.

\section{BULGULAR}

Araştırmaya toplam 549 kişi katılmış olup, bunların \%78,70'sinin kadın olduğu, yaş ortalamasının 34,74 yıl \pm 8,67 Standart Sapma (SS) olduğu, katılanların en küçüğünün 19 yaşında, en büyüğünün 64 yaşında olduğu, cinsiyete göre yaş ortalamaları arasında fark olmadığı görülmüştür ( $\mathrm{p}=0,631)$. Katılımciların \%9,40'ının lise ve altı, \%9,60’ının yüksek lisans/doktora düzeyi eğitim seviyesine sahip olduğu, \%61,20'sinin evli olduğu ve yine \%61,20'sinin yaşayan en az bir çocuğu olduğu saptanmıştır (Tablo 1).

Araştırmaya katılanların \%36,10'u cerrahi, \%63,90'1 ise cerrahi dışı bölümlerde çalışmaktadır. Cerrahi olarak sınıflandırılan kategoride ameliyathane, acil, anestezi, genel cerrahi, göz hastalıkları, kadın hastalıkları, ortopedi, üroloji, kalp damar hastalıkları, kulak burun boğaz hastalıkları yer alırken; cerrahi dışı olarak sınıflandırılan kategoride laboratuvar, pediatri, dahiliye, enfeksiyon hastalıkları, fiziksel tıp ve rehabilitasyon, gögüs hastalıkları, kardiyoloji, radyoloji, kan merkezi, psikiyatri, nöroloji yer almıştır.

Katılımcı sağlık çalışanlarının \%71,90'nını ebe ve hemşireler, \%8,60'inı laborantlar, \%6,10'nunu doktorlar, \%9,20'sini teknikerler (röntgen, anestezi, sağlık, radyoloji) oluşturmaktadır. Çalışanların \%36,70’i en az bir kronik hastalık beyan eder iken, alerji sıklığının \%23,20 olduğu görülmüştür.

Katılımcıların \%29,30'unun halen sigara içtiği, \%63,70’inin hiç sigara içmediği görülürken, alkol kullanma oranı ise
\%2,20 olmuştur.

\begin{tabular}{|c|c|c|}
\hline \multicolumn{3}{|c|}{$\begin{array}{l}\text { Tablo 1. Araştırmaya Katılan Sağlık Çalışanlarının } \\
\text { Sosyodemografik Özellikleri }\end{array}$} \\
\hline Özellikler & Sayı $(\mathrm{N})$ & Yüzde (\%) \\
\hline \multicolumn{3}{|l|}{ Cinsiyet $(\mathrm{N}=549)$} \\
\hline Erkek & 117 & 21,3 \\
\hline Kadın & 432 & 78,7 \\
\hline \multicolumn{3}{|l|}{ Yaș $(\mathrm{N}=532)$} \\
\hline $18-34$ & 264 & 49,6 \\
\hline $35-44$ & 202 & 38,0 \\
\hline 45 ve üzeri & 66 & 12,4 \\
\hline \multicolumn{3}{|c|}{ Öğrenim Durumu (N=479) } \\
\hline Lise ve altı & 45 & 9,4 \\
\hline Yüksekokul & 96 & 20,0 \\
\hline Üniversite & 292 & 61,0 \\
\hline Yüksek lisans/doktora & 46 & 9,6 \\
\hline \multicolumn{3}{|c|}{ Medeni Durumu $(\mathrm{N}=539)$} \\
\hline Evli & 330 & 61,2 \\
\hline Bekar & 200 & 37,1 \\
\hline Dul/Boşanmış & 9 & 1,7 \\
\hline \multicolumn{3}{|l|}{ Çocuk Sayısı (N=493) } \\
\hline Yok & 191 & 38,7 \\
\hline Bir & 110 & 22,3 \\
\hline İki & 154 & 31,2 \\
\hline Üç ve üzeri & 38 & 7,7 \\
\hline \multicolumn{3}{|l|}{ Çalıştığı Yerleşke $(\mathrm{N}=547)$} \\
\hline Merkez & 313 & 57,2 \\
\hline Korucuk & 129 & 23,6 \\
\hline Doğumevi & 105 & 19,2 \\
\hline
\end{tabular}

Çalışanların ailelerindeki kronik hastalık mevcudiyeti sorgulandığında \%54,40’ı ailelerinde kronik hastalık olduğunu belirtmiş olup, bu kronik hastalıkların \%29,70'inin hipertansiyon, \%19,40'inın diyabet, \%15,80'inin kalp hastalığı, \%11,40’ının kanser, geri kalan \%12,90’ının Kronik Obstriktif Akciğer Hastalığı (KOAH), tiroid ,astım gibi hastalıklar olduğu cevabı alınmıştır.

Araştırmaya katılan sağlık çalışanlarında bazı semptomların bulunma durumuna bakıldığında en sık semptom \%27,20'lik bir oranla eklem ağrısı olurken, ardından 
\%19,60 ile sırt ağrısı ve \%15,40 ile balgamlı öksürük gelmiştir.

Sağlık göstergeleri cinsiyete göre karşılaştırıldı̆̆ında; çarpıntı, sırt ağrısı, ishal-kabızlık, eklem ağrısı, alerjisi olma durumlarının her biri kadınlarda yüksek olmak üzere, aradaki fark istatiksel olarak anlamlı bulunmuştur (Tablo 2).

\begin{tabular}{|c|c|c|c|c|c|}
\hline \multirow[b]{2}{*}{$\begin{array}{l}\text { Semptomlar- } \\
\text { Hastalık-Öykü }\end{array}$} & \multicolumn{2}{|c|}{ Erkek } & \multicolumn{2}{|c|}{ Kadın } & \multirow[b]{2}{*}{${ }^{\star} \mathbf{P}$} \\
\hline & Sayı & $\%$ & Sayı & $\%$ & \\
\hline Balgamlı öksürük & 11 & 9,6 & 73 & 17,0 & 0,054 \\
\hline Nefes darlığ 1 & 7 & 6,1 & 46 & 10,7 & 0,145 \\
\hline Göğüs ağris1 & 6 & 5,3 & 29 & 6,8 & 0,563 \\
\hline Çarpıntı & 5 & 4,4 & 64 & 14,9 & 0,003 \\
\hline Sırt ağrısı & 14 & 12,3 & 92 & 21,5 & 0,028 \\
\hline İshal-kabızlık & 9 & 7,9 & 70 & 16,4 & 0,023 \\
\hline Eklem ağrısı & 19 & 16,7 & 129 & 30,0 & 0,004 \\
\hline Kalp hastalığı & 4 & 3,5 & 20 & 4,7 & 0,591 \\
\hline Şeker hastalığ 1 & 1 & 0,9 & 17 & 4,0 & 0,101 \\
\hline Böbrek hastalığı & 1 & 0,9 & 15 & 3,5 & 0,142 \\
\hline Sarılık & 4 & 3,5 & 4 & 0,9 & 0,042 \\
\hline Mide ülseri & 6 & 5,3 & 34 & 7,9 & 0,344 \\
\hline İşitme kaybı & 7 & 6,1 & 13 & 3,0 & 0,117 \\
\hline Görme bozukluğu & 34 & 29,8 & 120 & 28,0 & 0,707 \\
\hline Sinir sistemi hastalığ 1 & 1 & 0,9 & 14 & 3,3 & 0,169 \\
\hline Deri hastalığ & 4 & 3,5 & 35 & 8,2 & 0,086 \\
\hline $\begin{array}{l}\text { Hastanede yatış } \\
\text { öyküsü olan }\end{array}$ & 49 & 43,0 & 246 & 56,9 & 0,008 \\
\hline Ameliyat öyküsü olan & 49 & 43,4 & 238 & 55,2 & 0,025 \\
\hline $\begin{array}{l}\text { Halen tedavisi devam } \\
\text { eden }\end{array}$ & 13 & 11,3 & 99 & 22,9 & 0,006 \\
\hline Alerjisi olan & 13 & 11,4 & 113 & 26,3 & 0,001 \\
\hline İlaç alerjisi & 1 & 0,9 & 49 & 11,4 & 0,001 \\
\hline
\end{tabular}

Çalışanların \%7,10’u meslek hayatları boyunca en az bir kez iş kazası geçirmiştir. İş kazalarının üçü düşme olup 27 kişi de parmağına iğne battığını beyan etmiştir.

Araştırmaya katılan sağlık çalışanlarının bölümleri, cerra- hi ve cerrahi dışı olarak sınıflandırıldığında, ishal-kabızlık, eklem ağrısı semptomlarının sıklıkları cerrahi branşlarda anlamlı olarak yüksek bulunurken, diğer kronik hastalıkların dağılımı ile ilgili istatistiksel olarak anlamlı bir farka rastlanmamıştır (Tablo 3).

\begin{tabular}{|c|c|c|c|c|c|}
\hline \multirow[t]{2}{*}{ Semptom-Öykü } & \multicolumn{2}{|c|}{ Cerrahi } & \multicolumn{2}{|c|}{ Cerrahi Dışı } & \multirow{2}{*}{${ }^{\star} \mathbf{P}$} \\
\hline & Sayı & $\%$ & Sayı & $\%$ & \\
\hline Sırt ağrısı & 45 & 23,3 & 52 & 17,0 & 0,082 \\
\hline Eklem ağrısı & 70 & 36,1 & 68 & 22,1 & 0,001 \\
\hline $\begin{array}{l}\text { İş kazası geçirme } \\
\text { öyküsü }\end{array}$ & 13 & 6,7 & 29 & 9,4 & 0,294 \\
\hline $\begin{array}{l}\text { İğne batma öyküsü } \\
\text { olan }\end{array}$ & 7 & 4,7 & 19 & 7,8 & 0,232 \\
\hline
\end{tabular}

Semptomlar görev dağılımına göre değerlendirildiğinde, hemşire ve ebelerde eklem ağrısı sıklığ1 \%30,70, sırt ağrısı sıklığı \%20,70 iken, diğer sağlık personelinde daha düşük olarak eklem ağrısı \%17,60, sırt ağrısı sıklığı ise \%15,70 olarak saptanmıştır $(\mathrm{p}=0,002, \mathrm{p}=0,247)$.

Erkek sağlık çalışanlarının \%15,30'unda, kadın sağlık çalışanlarının \%9,50'sinde; toplamda ise \%10,70'inde öykü ve kan basıncı ölçümlerine göre hipertansiyon saptanmıştır (Şekil 1).

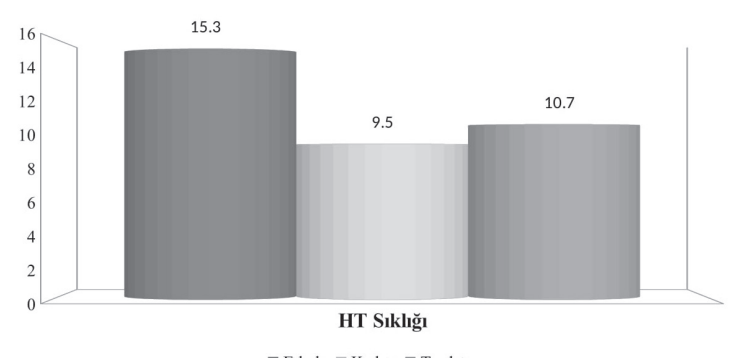

Şekil 1. Araştırmaya Katılan Sağlık Çalışanlarında Hipertansiyon Sıkliğı (HT: Hipertansiyon) 
Araştırmaya katılan sağlık çalışanlarında obezite sıklığı \%11,50 ( erkeklerde \%14,90; kadınlarda \%10,60 ) olarak hesaplanmıştır (Şekil 2).

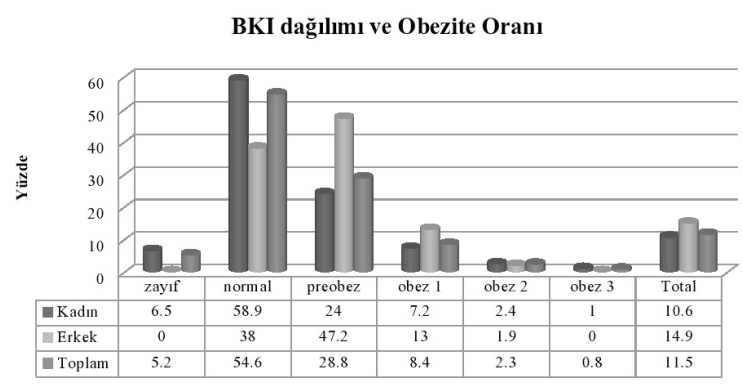

Şekil 2. Araştırmaya Katılan Sağlık Çalışanlarının Cinsiyete Göre Beden Kitle Indekslerinin Dă̆ılımı ve Obezite Oranları (BKİ: Beden Kitle İndeksi)

Çalışanların bazı sağlık göstergeleri, cinsiyete göre değerlendirildiğinde erkeklerin sistolik ve diyastolik kan basınçları, beden kitle indeksi değerleri anlamlı olarak yüksek bulunurken, sadece nabız değerleri kadınlarda erkeklerden anlamlı olarak yüksek saptanmıştır (Tablo 4).

\begin{tabular}{|c|c|c|c|c|c|c|}
\hline \multicolumn{7}{|c|}{$\begin{array}{l}\text { Tablo 4. Araștırmaya Katılan Sağlık Çalıșanlarının Bazı Sağlık } \\
\text { Göstergelerinin Cinsiyete Göre Dağılımı }\end{array}$} \\
\hline & $\begin{array}{l}\text { Orta- } \\
\text { lama }\end{array}$ & $\begin{array}{c}\text { Stan- } \\
\text { dart } \\
\text { sapma }\end{array}$ & $\begin{array}{l}\text { Ortan- } \\
\text { ca }\end{array}$ & EBD & EKD & ${ }^{*} \mathbf{p}$ \\
\hline \multicolumn{7}{|c|}{ Sistolik tansiyon } \\
\hline Erkek & 118,7 & 11,6 & 120 & 160,0 & 90,0 & \multirow{2}{*}{$<0,001$} \\
\hline Kadın & 106,9 & 15,1 & 110 & 160,0 & 70,0 & \\
\hline \multicolumn{7}{|c|}{ Diastolik tansiyon } \\
\hline Erkek & 76,4 & 8,6 & 80,0 & 100,0 & 60,0 & \multirow{2}{*}{$<0,001$} \\
\hline Kadın & 67,7 & 9,9 & 70,0 & 110,0 & 50,0 & \\
\hline \multicolumn{7}{|l|}{ Nabiz } \\
\hline Erkek & 81,7 & 12,9 & 81,7 & 100,0 & 60,0 & \multirow{2}{*}{0,011} \\
\hline Kadın & 85,2 & 12,4 & 85,2 & 110,0 & 50,0 & \\
\hline \multicolumn{7}{|l|}{ BKİ } \\
\hline Erkek & 26,5 & 3,5 & 25,9 & 37,8 & 19,3 & \multirow{2}{*}{$<0,001$} \\
\hline Kadın & 24,2 & 4,9 & 23,4 & 58,3 & 16,4 & \\
\hline $\begin{array}{l}\text { * Stud } \\
\text { küçük }\end{array}$ & esti & $\begin{array}{l}\text { nilm } \\
\text { den }\end{array}$ & $\begin{array}{l}\text { EBD: } \\
\text { İndek }\end{array}$ & büyü & ğer, 1 & \\
\hline
\end{tabular}

Çalışanların \%92'sinin AKŞ değerlerinin normal, \%0,50'sinin diyabetik, \%7,40'ının ise prediyabetik değerlere karş1lık geldiği izlenmiştir. AKŞ ortalamaları cinsiyete göre karşılaştırıldığında kadınlar ve erkekler arasında anlamlı fark bulunmamıştır ( $\mathrm{p}=0,999)$. Kendilerinde diyabetes mellitus olduğunu beyan edenlerin sıklığı \%3,30 iken ailesinde diyabet olduğunu beyan edenlerin sıklığ 1 ise \%19,40’tır.

Çalışanların yaşları arttıkça diyabet, sinir sistemi hastalığı, görme ve işitme bozukluğu sıklığı artarken; eklem ağrısı, sırt ağrısı, mide ülseri, deri hastalıkları ve kalp hastalıklarının yaşa göre değişim göstermediği saptanmıştır. Diyabeti olanların yaş ortalamaları (39,8 yıl \pm 9,3 SS), olmayanlardan $(34,5$ yıl $\pm 8,6$ SS $)$ anlamlı şekilde yüksek bulunmuş$\operatorname{tur}(\mathrm{p}=0,011)$.

Erkek katılımcıların ortalama hemoglobin değerleri 14,85 $\mathrm{g} / \mathrm{dl} \pm 1,14$ SS iken, kadınların ortalama hemoglobin değerleri 12,42 g/dl \pm 1,21 SS’dir (Tablo 5).

\begin{tabular}{|c|c|c|c|c|c|}
\hline \multicolumn{6}{|c|}{$\begin{array}{l}\text { Tablo 5. Araştırmaya Katılan Sağlık Çalışanlarının Cinsiyete } \\
\text { Göre Kan Sayımı Parametrelerinin Dağılımı }\end{array}$} \\
\hline $\begin{array}{l}\text { Özel- } \\
\text { likler }\end{array}$ & $\begin{array}{l}\text { Ortala- } \\
\text { ma }\end{array}$ & $\begin{array}{l}\text { Standart } \\
\text { sapma }\end{array}$ & Ortanca & EKD & EBD \\
\hline \multicolumn{6}{|c|}{ Beyaz küre } \\
\hline Erkek & 7,09 & 1,61 & 7,09 & 2,44 & 13,50 \\
\hline Kadın & 7,10 & 1,89 & 6,95 & 2,45 & 17,20 \\
\hline \multicolumn{6}{|c|}{ Hemoglobin } \\
\hline Erkek & 14,85 & 1,14 & 14,90 & 11,20 & 17,50 \\
\hline Kadın & 12,42 & 1,21 & 12,50 & 7,39 & 15,70 \\
\hline \multicolumn{6}{|c|}{ Hematokrit } \\
\hline Erkek & 44,74 & 3,83 & 44,70 & 33,90 & 66,30 \\
\hline Kadın & 37,59 & 3,91 & 37,90 & 23,10 & 49,70 \\
\hline \multicolumn{6}{|l|}{ Platelet } \\
\hline Erkek & 227,34 & 51,17 & 226,00 & 121,00 & 344,00 \\
\hline Kadın & 255,16 & 72,90 & 247,50 & 108,00 & 545,00 \\
\hline \multicolumn{6}{|c|}{ Lenfosit \% } \\
\hline Erkek & 33,24 & 9,08 & 34,60 & 2,83 & 54,90 \\
\hline Kadın & 31,33 & 8,46 & 32,00 & 2,94 & 50,00 \\
\hline \multicolumn{6}{|c|}{ Nötrofil \% } \\
\hline Erkek & 54,26 & 10,58 & 53,70 & 5,30 & 87,20 \\
\hline Kadın & 57,81 & 9,86 & 57,60 & 7,60 & 88,30 \\
\hline
\end{tabular}




\begin{tabular}{|c|c|c|c|c|c|}
\hline \multicolumn{6}{|c|}{ Eozinofil \% } \\
\hline Erkek & 2,49 & 1,99 & 2,11 & 0,04 & 13,80 \\
\hline Kadın & 1,96 & 1,38 & 1,38 & 0,01 & 9,33 \\
\hline
\end{tabular}

\section{TARTIŞMA}

Çalışanların sağlık problemleri bütüncül bir bakış açısıyla ele alındığında, ilk sırada genel sağlık sorunları gelmekte olup bunu iş kazaları ve meslek hastalıkları takip etmektedir. Çalışmada değerlendirilen sağlık çalışanlarında, meslek hayatları boyunca en az bir kez iş kazası geçirenlerin oranının \%7,10 olduğu ve en sık iş kazası nedeninin iğne batması olduğu görülmektedir. Literatürde hastane çalışanlarının geçirdiği iş kazalarının tespit edilmesi, alınması gereken önlemler ve periyodik tarama programlarının değerlendirildiği birçok çalışma bulunmaktadır. Çopur ve ark. hastane çalışanlarının en fazla geçirdiği iş kazasının, çalışma verileriyle uyumlu olarak iğne batması olduğunu belirtmişlerdir. ${ }^{12}$ Yine yapılan bazı çalışmaların sonuçları da delici kesici alet yaralanmalarının görülme sıklığının yüksek olduğunu göstermektedir. Bu çalışmalarda iş kazalarının yanı sıra çalışanların iş kazalarından korunma konusunda bilgi düzeyleri ve aldıkları eğitimler de değerlendirilmiştir. Çalışanların tamamı olmasa da, büyük kısmının iş kazaları ve alınması gereken önlemler konusunda düzenli aralıklarla eğitime tabi tutulduğu ve eğitim alan personellerin almayanlara göre iş kazası geçirme oranının daha düşük olduğu belirtilmiştir. ${ }^{13,14}$

Yapılan çalışmalar bütünüyle değerlendirildiğinde hastane çalışanlarında iş kazası görülme oranları \%15-33 aralığında değişmekte iken çalışmamızda bu oranın daha düşük tespit edilmesinin, çalışmamızın yapıldığı sağlık tesisinde çalışanlara verilen eğitimlerin, çalışanların bireysel özverilerinin ve çalışma şartları değişkenliğinin sonucu olabileceğini düşündürmektedir.

Katılımcıların iş kazası öyküleri sorgulandığında iş kazası olarak yalnızca iğne batması, kesici delici alet yaralanmaları ve düşmelerin algılandığı görülmektedir. Oysaki BLS verilerine göre ABD'de sağlık kurumlarında şiddetin, iş kazası nedenleri arasında önemli bir yeri olduğu görülmektedir. Çalışmamızda şiddet olayları katılımcılar tarafından iş kazası olarak beyan edilmemiştir. Bunun nedeni 6331 sayılı yasanın işveren, işveren temsilcileri ve çalışanlar tarafından yeterince anlaşılmaması olabilir. Yasa, çalışanın başına gelen işle ilgili hertürlü olumsuzluktan, işvereni sorumlu tutmaktadır. Bu nedenle ülkemizde de son yıllarda sağlık çalışanlarına yönelik artan şiddet olaylarının 6331 sayılı İş Sağlığı ve Güvenliği kanunu kapsamında iş kazası olarak değerlendirilmesi gerektiği kanısındayız.

Kas iskelet sistemine bağlı meslek hastalıkları ya da işle ilgili hastalıklar kapsamında değerlendirilebilecek olan eklem ve sırt ağrısı yakınmalarının görülme sıklıkları, bu çalışmada sırasıyla \%27,20 ve \%19,60 olarak saptanmıştır. Literatürde sağlık çalışanlarında sırt ağrısı görülme sıklığı \%22,50-71.00 arasında değişirken, kas iskelet sistemi rahatsızlıkları bütünüyle değerlendirildiğinde yine \%22-82 gibi geniş bir aralıkta değişkenlik göstermektedir. ${ }^{19-21} \mathrm{Ge}-$ nel olarak bu çalışmanın sonuçlarına yakın sonuçlar olduğu görülse de yapılan çalışmaların sonuçları arasında ciddi farklılıklar olduğu da görülmektedir. Bunun nedeni olarak yapılan çalışmalarda kullanılan ağrı değerlendirme skalaları arasındaki değişkenliklerle birlikte, çalışmaların yapıldığı sağlık tesislerinin çalışma şartları, fiziki koşulları ile çalışanların yaş dağılımları, sağlık meslek gruplarının kendi içerisindeki değişkenlikleri gibi faktörler düşünülebilir. Sağlık çalışanları içinde meslek gruplarının ayrı ayrı değerlendirmesinde; hemşirelerde sırt ağrısı oranının diğer sağlık personelinden üç ila altı kat daha fazla görüldüğü ifade edilmektedir. ${ }^{20,24}$ Çalışmamızda da hemşirelerdeki sırt ağrısı ve eklem ağrısı sıklıkları diğer sağlık personelinden yüksek bulunmuştur.

Hemşirelerde sırt ağrısına en fazla neden olabilecek faktörlerin; ağır kaldırma ( hastaları kaldırma ve pozisyon vermede olduğu gibi ), yanlış çalışma postürü, aşırı efor, tekrarlayıcı hareketler, ekstreme postürde uzun süre kalma olduğu tespit edilmiştir, ${ }^{25-27}$ Laboratuvar çalışanları için ise 
ergonomik risk faktörlerinin; gürültü, oturulan sandalye ve taburenin oturma pozisyonu, iş stresi, titreşim, çalışma hızı, ortam sıcaklığı olduğu tespit edilmiştir. ${ }^{17}$

İş kazaları ve meslek hastalıklarının yanı sıra sağlık çalışanlarında, toplumda sık görülen hipertansiyon, obezite ve diyabet gibi kronik hastalık durumlarının da değerlendirildiği çalışmamızda, sistolik ve diyastolik kan basıncı değerleri erkeklerde kadınlardan daha yüksek olmak üzere hipertansiyon görülme oranı \%10,70 olarak tespit edilmiştir. Toplum tabanlı prevelans çalışmalarında (PatenT 1-2, CREDIT, TURDEP 1-2, TKrHRF) ise bu oran \%30,3033.00 arasında değişmektedir. ${ }^{28-32}$

Cinsiyetler kendi içinde değerlendirildiğinde ise hipertansiyon sıklığı; kadınlarda daha düşük olarak \%9,50, erkeklerde ise \%15,30 olarak tespit edilmiştir. Yapılan prevelans çalışmalarının sonuçları kadınlarda hipertansiyon görülme oranının erkeklerden daha yüksek olduğunu göstermektedir. $\mathrm{Bu}$ çalışmalar kadınlarda hipertansiyon görülme oranının \%26,10-36,10 aralığında; erkeklerde ise \%21,10-30.00 aralığında değiştiğini göstermektedir. Çalışma verilerimizden çıkarılan sonuçlar ile literatür verileri arasındaki değişkenliğin; değerlendirdiğimiz çalışan grubunun yaş ortalamalarının toplum ortalamasından daha düşük olmasından, çalışanların mesleki kazanımlarının hipertansiyondan korunmada ve kontrol altında tutmada etkili olmasından kaynaklandığını düşünüyoruz. Kadın çalışanlarda ise hipertansiyon görülme oranının daha düşük saptanmasının, çalışan kadınların farkındalıklarının, öz bakımlarının ve iş temposu nedeniyle fiziksel aktivitelerinin toplum ortalamasına göre daha yüksek olmasından kaynaklanabileceği kanaatindeyiz.

Ülkemizdeki obezite prevelansı çeşitli ulusal çalışmalarda (TURDEP 1-2, TBSA, TEKHARF) \%19-43 arasinda değişirken, bu çalışmalardan TURDEP-2 ülkemizdeki obezite prevelansını 2016 yılı itibariyle DSÖ verileriyle de uyumlu olarak \%29,50 (kadın \%35, erkek \%23,9) olarak belirtmektedir. ${ }^{28,33,34}$ Çalışmamızda ise obezite sıklığı erkeklerde daha yüksek olmak üzere, \%11,50 (erkeklerde $\% 14,90$, kadınlarda \%10,60) olarak saptanmıştır. Toplum geneli obezite prevelansının çalışmamızdakinden yüksek olduğu, ayrıca çalışmamızın aksine obezite prevelansının kadınlarda daha yüksek olduğu görülmektedir. Bunun birkaç nedeni olabilir; birincisi bu çalışmanın yaş ortalaması toplum bazlı çalışmalara göre oldukça düşüktür. İkinci neden olarak toplum bazlı çalışmalarda kadın katılımcıların büyük çoğunluğunun daha az fiziksel aktivite gösteren, iş hayatı olmayan kesimden olmasıdır. Bu çalışmada ise katılımcıların \%78,70'ini aktif çalışan kadın sağlık personeli oluşturmaktadır. Kadınların BKİ’lerinin (24,2 kg/m2), erkeklerden $(26,5 \mathrm{~kg} / \mathrm{m} 2)$ istatistiksel olarak anlamlı derecede düşük çıkması kadın sağlık çalışanlarının bu konuya erkeklerden daha fazla dikkat ediyor olmalarının bir sonucu olabilir. Çalışmamızda normal BKİne sahip katılımcıların oranının $(\% 54,60)$, toplum temelli çalışmaların (\%26) iki katından fazla olması, yukarıda değinilen açıklamaları desteklemektedir. ${ }^{34}$ Literatürde ayrıca ülkemizin Avrupa'da obezitenin en sık görüldügüu ülke olduğu, yıllar içinde ülkemiz ve dünya genelinde obezite prevelansında çok ciddi artış olduğu önemle vurgulanmaktadır. ${ }^{34,35}$

Son on yılda yapılan ulusal çalışmalarda (CREDIT, PURE, TURDEP 2, TKrHRF) ülkemizde diyabet prevelansı, araştırma gruplarındaki yaş farklılıkları ve diyabet tanı kriterleri arasındaki farklılıklar nedeniyle \%11-16 arasında değişmektedir. ${ }^{29,30,31,36}$ Prediyabet prevelansı da benzer şekilde \%10-16 arasında değişkenlik göstermektedir. Yine bahsedilen çalışmalar sonucunda ülkemizde diyabet sıklığı açısından kadın erkek farkının kapanmış olduğu izlenmekte olup, bizim çalışmamızda da literatüre benzer şekilde açlık kan şekeri ortalamaları cinsiyete göre değerlendirildiğinde kadınlarla erkekler arasında anlamlı fark izlenmemiştir. Çalışmamızdaki diyabet görülme sıklığ1nın $(\% 0,50)$ literatür verilerinden çok daha düşük olduğu görülmekte olup, bu durumun çalışmaya katılanların yaş ortalamasının düşüklüğüyle, katılımcıların fiziksel açıdan hareketli, aktif çalışan kişiler olmasıyla ve BKI’lerinin düşük olmasıyla ilişkilendirilebileceğini düşündük. Ancak 
prediyabet sıklığının $(\% 7,40)$ literatür verilerine daha yakın olması ve görece diyabet görülme sıklığından oldukça yüksek olması bize sağlık çalışanlarının mesleki kazanımları nedeniyle diyabet hakkındaki bilgi düzeyleri ve farkındalıklarının yüksek olmasının, bu bağlamda erken tanı ve hastalık süreci yönetimlerinin de daha sağlıklı olmasının sonucu olabileceğini düşündürmüştür.

Sağlık çalışanlarının zararlı alışkanlıklarının değerlendirilmesinde ise sigara ve alkol kullanımları sorgulanmıştır. Sigara birey ve toplum sağlığını tehdit eden alışkanlıkların başında gelmektedir. Son dönemde ülkemizde de ciddi politikalar üretilerek sigaraya karşı kapsamlı bir savaş başlatılmıştır. Toplumda genel kanı sağlık çalışanlarının sigara gibi zararlı alışkanlıklardan uzak durdukları yönünde olsa da çalışmamız verileri sağlık çalışanlarında da toplum ortalamalarıyla uyumlu sigara kullanımı olduğunu göstermektedir. ${ }^{37}$ Değerlendirdiğimiz sağlık çalışanları içinde sigara kullanım oranının \%29,30 olduğu tespit edilmiştir. Kadınlarda bu oran \%27,70 iken, erkeklerde \%35,30 olarak bulunmuştur. Sağlık çalışanlarının sigara kullanımları üzerine yapılan çalışmalarda kullanım oranları\%29,30-56,50 aralığında değişmektedir. Bu çalışmaların farklı zamanlarda ve farklı kurumlarda yapılmış olması çalışmamızla karşılaştırmayı zorlaştırsa da sağlık çalışanlarının sigara kullanımları üzerine bir fikir vermektedir. Sigaranın sağlığa zararlı etkilerini en iyi bilen ve çalışma alanlarında da gözlemleyen sağlık çalışanlarında dahi sigara kullanımının yüksekliği ve bırakma oranlarının düşüklüğü sigara bırakma hizmetlerinin yaygınlaştırılması, tedavi desteğinin sağlanması ve hizmet içi eğitimlerin arttırılması gerektiği sonucuna götürmektedir.

Alkol kullanan sağlık personeli oranı \%2,20 olarak hesaplanmış ve toplum ortalamasına ( $\% 13,20)$ göre anlamlı düzeyde düşük bulunmuştur. ${ }^{31}$ Yine sağlık çalışanlarının alkol kullanımının sağlığa zararlı olası etkileri konusunda bilgi düzeylerinin bu sonuç farklılıklarına neden olabileceği düşünülebilir. Bunun yanı sıra ülkemizde sosyal ve kültürel alışkanlıklar ile sosyal baskı faktörlerinin de so- nuçlara etki edebileceği unutulmamalıdır.

Sonuç olarak bu çalışmada, sağlık çalışanlarının genel sağlık durumları ve işle ilgili hastalıklar kapsamında ele alınabilecek hastalık semptomları, iş kazası ve kronik hastalıkların sıklıkları çalışan sağlığı bilgi formları üzerinden değerlendirilmiştir.

Problemlerin çözümü için öncelikle tanımlanmış olmaları gerektiği ve bu çalışmanın da sağlık çalışanlarının mesleki tehlike ve risklerine dikkat çekerek, bu riskleri azaltmaya ve bu konuda sağlık personelinin çalışma şartlarının iyileştirilmesi ve yaşam kalitelerinin yükseltilmesine yönelik, ileride yapılacak olan çalışmalara öncülük edecek tanımlayıcı bir araştırma olacağı görüşündeyiz.

\section{Araștırmanın Kısıtlılıkları}

Çalışmamız araştırmanın yapıldığg sağlık kurumundaki tüm personeli kapsamamaktadır. Sadece 2017 yılı içerisinde çalışan sağlığı biriminde değerlendirilen personelin durumunu yansıtmaktadır ve elde edilen bulgular çalışmaya dahil olanlara genellenebilir.

Çalışmamızın veri kaynağını oluşturan formdaki sorulardan biri de "iş kazası geçirdiniz mi?” sorusudur. Katılımcıların nelerin iş kazası tanımına girip girmediği konusundaki bilgi düzeyi ve algı farklılıklarından dolayı iş kazası oranlarımız düşük çıkmış olabilir.

Araştırmaya katılan sağlık çalışanlarının işe giriş ve aralıklı kontrol muayeneleri tam olmadığından, tespit ettiğimiz yakınmaların işle ilgili olduğunu iddia etmemiz mümkün değildir.

\section{Çalışma için T.C Sakarya Üniversitesi Tıp Fakültesi Girişimsel Olmayan Araştırmalar Etik Kurulun'dan 71522473/050.01.04/82 karar sayılı ve 02.04.2018 tarihli etik kurul onayı alınmıştır.}


Sakarya Tip Dergisi 2020;10(Özel Sayı):41-50

PEKDEMiR ve Ark.,Sağılk Çalışanlarının Genel Sağlık Durumları ve Sık Görülen Hastalıkları

\section{Kaynaklar}

1. US Department of Health and Human Services. National action plan to prevent healthcare-associated infections: roadmap to elimination.( USDHHS-2018)

2. https://www.ilo.org/global/lang--en/index.htm (Erişim tarihi:01.10.2018).

3. http://www.tuik.gov.tr/PreTablo.do?alt_id=1095 (Erişsim tarihi: 25.06.2020).

4. Özkan Ö, Emiroğlu N. Hastane sağlık çalı̧anlarına yönelik işçi sağllğı ve iş güvenliği hizmetleri. Cumhuriyet Universitesi Hemşirelik Yüksek Okulu Dergisi 2006;10:43-50.

5. http://www.sagliksen.org.tr/dosya/avrupa_c_s_d.doc (Erişim tarihi: 01.10.2018).

6. Karaca Y. Sağlık çalışanlarında iş sağglğı ve güvenliği. Yüksek Lisans Tezi. Beykent Üniversitesi, Sosyal Bilimler Enstitüsü, İstanbul, 2013

7. https://www.osha.gov/dsg/hospitals/ documents/1.2_factbook_508.pdf, (erișim tarihi: 03.10.2018).

8. Çalışkan D, Akdur R. (2001). Ankara Üniversitesi Tip Fakültesi Hastanesi’nde çalışan hemşirelerin kendi bildirimleri ile karşılaş̧ıkları mesleki riskler. Ankara Üniversitesi Tip Fakültesi Mecmuast 2001; 54(2):136.

9. https://www.tkd.org.tr/kilavuz/k03/91f3c.htm?wbnum=1115 (erişim tarihi:03.10.2018)

10. http://www.euro.who.int/en/health-topics/disease-prevention/nutrition/a-healthy-lifestyle/ body-mass-index-bmi erişim tarihi:03.10.2018

11. https://www.who.int/diabetes/publications/Definition\%20and\%20diagnosis\%20of\%20diabetes_new.pdf (erișim tarihi:03.10.2018)

12. Çopur Z, Varl B, Avşar M, Şenbaş M. Ege Üniversitesi Hastanesinde çalışan ev idaresi personelinin iş kazası geçirme durumlarının incelenmesi. Hacettepe Sağlık İdaresi Dergisi 2006; 9(2):155-176

13. Erkal S, Çoşkuner S. Bir hastanede çalışan ev idaresi personelinin iş kazası geçirme durumunun ve kazalardan korunmak için aldıkları önlemlerin incelenmesi. Hacettepe Sağllk İdaresi Dergisi 2010; 13(1):45-62

14. Kurt AÖ, Harmanoğulları ÜL, Ekinci Ö, Ersöz G. Bir üniversite hastanesi temizlik çallşanlarının biyolojik risk bilgi, tutum ve davranışları. Mersin Üniveristesi Sağlık Bilimleri Dergisi 2015; 8(2):37-47

15. Hignett S. Work-related back pain in nurses. Journal of Advanced Nursing 1996; 23:12381246.

16. Trinkoff AM, Lipscomb JA, Geiger-Brown J, Brady B. Musculoskeletal problems of the neck, shoulder, and back and functional consequences in nurses. American Journal of Industrial Medicine 2002; 41:170-178

17. Atasoy A, Keskin F, Başkesen N, Tekingündüz S. Laboratuvar çalışanlarında işe bağll kas-iskelet sistemi sorunları ve ergonomik risklerinin değerlendirilmesi. Sağlıkta Performans ve Kalite Dergisi 2010; 2(2):90-113.

18. Long MH, Bogossian FE, Johnston V. The prevalence of work-related neck, shoulder, and upper back musculoskeletal disorders among midwives, nurses, and physicians: a systematic review. Workplace Health Saf 2013; 61(5):223-229.

19. Nützi M, Koch P, Baur H, Elfering A. Work-Family conflict, task interruptions, and influence at work predict musculoskeletal pain in operating room nurses. Saf Health Work 2015; (6):329-337.

20. Mehrdad R, Sadat Shams-Hosseini N, Aghdaei S, Yousefian M. Prevalence of low back pain in health care workers and comparison with other occupational categories in Iran: $a$ systematic review. Iran J Med Sci 2016; 41(6): 467-478.
21. Choi HW, Kim YK, Kang DM, Kim JE, Jang BY. Characteristics of occupational musculoskeletal disorders of five sectors in service industry between 2004 and 2013. Ann Occup Environ Med 2017; 19;29:41.

22. Ribeiro T, Serranheira F, Loureiro H. Work related musculoskeletal disorders in primary health care. Applied Nursing Research 2017; 33:72 -77.

23. Saberipour B, Ghanbari S, Zarea K, Gheibizadeh M, Zahedian M. Investigating prevalence of musculoskeletal disorders among Iranian nurses: A systematic review and meta-analysis. Clinical Epidemiology and Global Health 2019;7:513-518

24. Cohen-Mansfield J, Culpepper 2nd WJ, Carter P. Nursing staff back injuries: prevalence and cost in long term care facilities. AAOHN J 1996; 44:9-17.

25. Retsas A, Pinikahana J. Manual handling activities and injuries among nurses: An Australian hospital study. Journal of Advanced Nursing 2000; 31:875-883.

26. Ramos DG, Arezes PM, Afonso P. Analysis of the return on preventive measures in musculoskeletal disorders through the benefite cost ratio: A case study in a hospital. International Journal of Industrial Ergonomics 2017; 60: 14-25.

27. Ribeiro T, Serranheira F, Loureiro H. Work related musculoskeletal disorders in primary health care. Applied Nursing Research 2017; 33:72 -77.

28. Satman I, Yilmaz T, Sengül A, Salman S, Salman F, Uygur S. et al. Population-based study of diabetes and risk characteristics in Turkey: Results of the Turkish Diabetes Epidemiology Study (TURDEP). Diabetes Care 2002; 25:1551-1556.

29. Süleymanlar G, Utaş C, Arinsoy T, Ateș K, Altun B, Altiparmak MR. et al. A population-based survey of Chronic REnal Disease In Turkey.(the CREDIT study). Nephrol Dial Transplant 2011; 26(6):1862-71.

30. Satman I, Omer B, Tutuncu Y, Kalaca S, Gedik S, Dinccag N. et al. Twelve-year trends in the prevalence and risk factors of diabetes and prediabetes in Turkish adults. European journal of epidemiology 2013; 28:169-180

31. Unal B, Ergör G, Sözmen K. Türkiye kronik hastalıklar ve risk faktörleri sıkllğı çalı̧̧ması. Sağlık Bakanlı̆̆. Ankara. 2013 ( https://sbu.saglik.gov.tr/Ekutuphane/Yayin/462 erișim tarihi:03.10.2018)

32. Sengul S, Akpolat T, Erdem Y, Derici U, Arici M, Sindel S. et al. Changes in hypertension prevalence, awareness, treatment and control of rates of Turkey (the PatenT study) in 2012. J Hypertens 2016; 34:1208-17.

33. Onat A, Karabulut A, Yazıcı M, Can G, Sansoy V. Türk yetișkinlerde hiperkolesterolemi ve hipertansiyon birlikteliği, sıklğına ve kardiyovaskuler riski öngördürmesine ilişkin TEKHARF çalıșmast verileri. Türk Kardiyoloji Derneği Arşivi 2004; 32:533-41.

34. Satman İ. Türkiye'de obezite sorunu. Türkiye Klinikleri J Gastroenterohepatol Special Topics 2016; 9(2):1-11.

35. NCD Risk Factor Collaboration, Di Cesare M, Bentham J, Stevens G, Zhou B, Danaei G. et al. Trends in adult body-mass index in 200 countries from 1975 to 2014: a pooled analysis 1698 population-based measurement studies with 19.2 million participants. Lancet 2016 387:1377-96

36. Oğuz A, Altuntaș Y, Karșıdağ K, Akalın AA, Calık B, Güleç S, Temizhan A, Göktan G, İmeryüz N. Türkiyede diabetes mellitus ve prediyabet prevalansı (PURE çalışması). 32. Türkiye Endokrinoloji ve Metabolizma Hastalıkları Kongresi Bildiri Özetleri Kitabı. Antalya. (2010) 37. http://www.halksagligiens.hacettepe.edu.tr/KYTA_TR.pdf, (Erişim Tarihi: 13.11.2018) 